\title{
A porta e suas múltiplas significações
}

\author{
Sylvia Cavalcante \\ Universidade de Fortaleza
}

\begin{abstract}
Resumo
A porta é um dos elementos mais antigos e fundamentais da estrutura espacial. Ela assume funções de barreira mecânica, térmica, visual e acústica. Assegura funções topológicas de junção ou disjunção entre os espaços para diferenciá-los ou fundi-los. Visando a compreendê-la em sua riqueza de significações, buscamos desvendar suas dimensões subjetivas, reconhecer o papel que tem nos relacionamentos sociais e expressar os estados psicológicos daí advindos. Este artigo evidencia também a possibilidade de se conhecer aspectos fundamentais da vida humana através da análise da inter-relação dos indivíduos com um elemento espacial. Do ponto de vista metodológico, este trabalho define-se, principalmente, como uma descrição apoiada numa reflexão fenomenológica.
\end{abstract}

Palavras-chave: porta; espaço; psicologia ambiental

\begin{abstract}
The door and its multiple meanings. The door is one of the oldest and most fundamental elements of the space structure. It takes over functions of a mechanical, thermal, visual, and acoustic barrier. It also assures topological functions of junctions or disjunctions between spaces to differentiate or to unite them. In order to understand the door in all its richness of meanings we searched for uncovering its subjective dimensions, recognizing the valuable role that it plays in social relationships and tried to indicate the psychological states that can arise from them. This article also makes evident the possibility of getting to know fundamental aspects of human ways of life through the analysis of the inter-relationship between individuals and a spatial element. From a methodological point of view this paper can be defined as a descriptive study supported by a phenomenological reflection.
\end{abstract}

Key words: door; space; environmental psychology

A

Psicologia Ambiental estuda as inter-relações humano-ambientais. Por conseguinte, dirige seu olhar ora para o indivíduo com seus diversos comportamentos e atitudes, ora para o ambiente, sob forma de objetos, espaços e sociedades. Isto porque a noção de ambiente para a Psicologia Ambiental inclui o indivíduo. "A pessoa tem propriedades ambientais tanto quanto propriedades psicológicas individuais. O homem é ele mesmo um componente ambiental e, como ele interage com seu meio, ajuda a determinar a natureza do meio e seus efeitos sobre suas ações” (Ittelson, Proshansky, Rivlin \& Winkel, 1974, p. 12). Na verdade, as inter-relações do homem com o meio-ambiente constituem o objeto de estudo da Psicologia Ambiental e elas são configuradas através de uma démarche que se inicia privilegiando um dos lados dessa relação. O encaminhamento habitual consiste em partir do estudo de um só comportamento, determinado a priori, para descobrir as relações que este comportamento mantém com o meio ambiente. A démarche adotada por mim vai ser exatamente a inversa: partir de um elemento do espaço para descobrir e estudar as diversas condutas a ele relacionadas.

Sob essa perspectiva, portanto, o método deste trabalho é inclusivo (Moles \& Rohmer, 1979; Schwach, 1989) porque ele possibilita a descoberta imediata de um feixe de aspectos psicológicos e sociais - sentimentos, atitudes, comportamentos - vinculados a um mesmo elemento do espaço, ao invés do método habitual, o exclusivo, que consiste na análise de um único fenômeno psicológico ou social a propósito do qual se examina seu contexto.

De início, esta abordagem coloca problemas de concepção de trabalho, entre outros, quanto às múltiplas possibilidades de pesquisa que se descortinam. Com efeito, ela também exige que o pesquisador selecione os aspectos que lhe pareçam mais relevantes. No entanto, tem a vantagem de cons- 
tituir um sistema explicativo dos fenômenos ligados ao elemento estudado. Este tipo de procedimento permite uma maior rapidez na pesquisa de soluções práticas para problemas concretos que possam se apresentar, e se aplica, também, mutatis mutandis, a muitos elementos do ambiente cotidiano, como a janela, o elevador, a escada..., enfim, a uma série de micro-espaços da vida diária.

Observa-se que o contato cotidiano com a porta a torna banal, impedindo que se possa avaliar claramente sua importância. Seu uso freqüente faz esquecer que não se pode eliminá-la, ou dela prescindir. No entanto, é justamente a convivência diária que faz a porta significativa. A porta é um dos elementos mais antigos e fundamentais da estrutura espacial. Desde o tempo das cavernas, desde que o homem passou a delimitar um espaço para se proteger do frio, do calor e dos perigos do exterior, ele tentou fechar o espaço com uma barreira material - uma cerca, um pedaço de madeira ou qualquer outro obstáculo - para que pudesse se movimentar à vontade, em seu interior. Assim, introduziu em sua linguagem a idéia de abertura e de fechamento.

A porta assume, portanto, funções de barreira mecânica, térmica, visual e acústica. Assume, também, funções topológicas de junção ou disjunção entre os espaços que se quer diferenciar ou fundir. Entretanto, para compreendê-la em todos os seus aspectos precisamos ultrapassar as abordagens específicas do engenheiro e do arquiteto. Importa desvendar suas dimensões subjetivas, reconhecer o papel que tem nos relacionamentos sociais e expressar os estados psicológicos advindos deste contato. É a partir dessa perspectiva que as relações do indivíduo com a porta e com o espaço em geral passam a ser examinadas neste trabalho, chamandose a atenção para a plasticidade desta estrutura.

Certamente, muitos dos resultados enunciados podem parecer evidentes ao leitor que tem apenas que se reportar a sua experiência do dia a dia para encontrar confirmação. Na verdade, é talvez próprio de tais objetos ter um certo "ar de evidência” quando são analisados. Entretanto, a atitude de muitos construtores, arquitetos e decoradores que freqüentemente concebem seus projetos de forma arbitrária, sem levar em consideração as variáveis psicológicas que entram em jogo, revela que estes resultados não são tão evidentes quanto parecem.

Do ponto de vista metodológico, este trabalho definese, principalmente, como uma descrição apoiada numa reflexão fenomenológica. A análise dos aspectos da porta e dos comportamentos a ela relacionados parte de suas características externas. Assim, pela descrição, tenta-se reconstituí-los tais como se manifestam, antes de qualquer tematização. Por certo ela não esgota o tema. Vários outros aspectos seriam interessantes e mesmo indispensáveis a um estudo completo. No entanto, três objetivos principais orientam esta análise: expor que a idéia de porta é, em si mesma, plena de significação; demonstrar que é possível conhecer aspectos de nossa vida social e psíquica através do estudo da relação que se estabelece com um elemento espacial; e enfim, contribuir para uma teoria dos micro-espaços.

\section{A porta: uma estrutura espacial rica}

Comparando a porta a estruturas espaciais similares - a abertura e o muro - observam-se mais facilmente suas propriedades materiais e é possível defini-la como um sistema com topologia variável: uma abertura e um fechamento. Esses estados cumprem funções - o isolamento e a passagem ou a comunicação - que correspondem à satisfação de necessidades humanas opostas, recorrentes no tempo e no espaço. O eixo da dobradiça, em torno do qual a divisória móvel é articulada, permite variar sua posição e, ao mesmo tempo, manter a unidade do sistema. (Latour, 1992).

A particularidade que sobressai da análise das relações do indivíduo com esta reunião topológica é a escolha que ela lhe propõe. Ele pode tê-la como uma abertura ou como um fechamento. E o que significa esta possibilidade de escolha que a porta oferece? Cada um de seus aspectos - abertura ou fechamento - propicia características específicas ao ambiente. A atmosfera criada por uma porta fechada é, em certa medida, antinômica àquela assegurada por uma porta aberta. Um mesmo cômodo mostra-se isolado, calmo, íntimo, tendo sua porta fechada e pode tornar-se dinâmico, estimulante e barulhento, quando sua porta está aberta. Escolher entre um e outro destes estados significa poder agir sobre seu ambiente. A porta, portanto, oferece ao homem a possibilidade de não admitir passivamente a influência do ambiente: através dela, ele pode intervir em seu espaço criando uma variedade de climas e, ainda assim, conservar suas características fundamentais. Abrindo-se a porta, pode-se estabelecer conexões entre os espaços, criar perspectivas de interesses diversos, descortinar espaços vizinhos. Através da abertura, o olhar pode buscar outros mundos. Contrariamente, fechando-se a porta, a privacidade é favorecida: o homem pode voltar-se para si mesmo e desenvolver atividades privilegiadas. Em suma, através da porta, o homem pode criar uma variedade ambiental. Deste ponto de vista, a porta é uma fonte de complexidade e dinamismo no ambiente a disposição do homem.

Poder escolher entre uma porta aberta e uma porta fechada significa, ainda, ter liberdade. É importante lembrar que "em qualquer contexto ambiental, o indivíduo tenta organizar seu meio físico de maneira a maximizar sua liberdade de escolha” (Proshansky, Ittelson \& Rivlin, 1976, p. 172). A porta é um dos equipamentos do espaço construído que asseguram esta liberdade, tendo em vista que oferece sempre uma alternativa. Trata-se de uma escolha certamente binária, porém, contínua e não irreversível, porque se re-apresenta após cada decisão. Dito de outra forma, a opção por determinado tipo de ambiente criado através da porta não exclui a chance de modificá-lo posteriormente. Por conseguinte, pela escolha que oferece e pelas possibilidades deste recurso, ela pode ser vista como uma fonte de liberdade no espaço.

Este sistema com topologia variável apresenta ainda uma outra faceta: permitir a participação do sujeito no ordenamento de seu ambiente. É evidente que, admitindo a escolha, a porta acarreta uma ação, ação esta que vai além do ato cinestésico de movimentá-la. Fechar ou abrir uma porta requer uma decisão que supõe um senso de autonomia e de responsabilida- 
de: significa tomar parte na disposição de seu ambiente. É importante salientar, aqui, o interesse desta relação dinâmica para o desenvolvimento da personalidade: inicialmente, durante os primeiros anos de vida, quando a ação de deslocar uma porta é incorporada pelo sistema motor da criança e, mais tarde, especialmente durante o período da adolescência, quando este ato passa a constituir uma conduta consciente e responsável, uma expressão de si mesmo. Ela contribui para o desenvolvimento da autonomia e mantém o sentimento de integridade do indivíduo. Através do ato de abrir e de fechar uma porta, o indivíduo exerce uma ação sobre seu meio, participa de sua organização, adquirindo, conseqüentemente, um sentimento de domínio. Desse modo, a porta possibilita ao homem exercer a condição de sujeito de sua própria existência.

Estas considerações geralmente passam despercebidas da maioria das pessoas. É muito comum a valorização das grandes ações, como a construção de uma casa ou o nascimento de um filho, confirmada pelo dito popular: "Todo homem, durante sua vida, deve ter um filho, construir uma casa e escrever um livro". Deve-se admitir, no entanto, que, apesar de pequeno, o ato de abrir, fechar ou passar por uma porta, merece atenção por sua freqüência.

Moles (1972) e Gregory (1988), entre outros, evidenciam que, psicologicamente, os seres humanos preferem os ambientes complexos, contanto que sejam fortemente estruturados, isto é, possuam uma complexidade organizada. A partir do que foi reportado, observa-se que porta é fonte de complexidade no ambiente, embora a responsabilidade em regular esta propriedade seja legada ao sujeito através da liberdade de escolha que lhe é dada. Assim sendo, a porta pode ser considerada uma estrutura espacial rica - rica em si mesma e pela relação que ela propõe.

\section{A porta em espera}

É concebível um espaço construído sem porta? Não, pelo menos em se tratando de um espaço destinado ao uso cotidiano. Suponhamos que para adentrarmos um certo espaço de uso freqüente tivéssemos de recorrer a uma escada ou quebrar parcialmente o muro e depois reconstruí-lo. Indiscutivelmente, tal situação requereria um enorme dispêndio de energia e seria certamente considerada insensata.

Não se tem notícia de quando o tabique móvel, tal como é concebido hoje, veio se conjugar à abertura. Sabe-se que, no entanto, no tempo dos egípcios ele já existia. Grande número das funções exercidas pela divisória móvel foi descrito aqui. Ela é o elemento chave da estrutura porta, tal como a concebo: um sistema com topologia variável.

Neste item, chamo a atenção, todavia, para a relativa indispensabilidade da porta enquanto abertura. Observa-se que os deslocamentos dentro dos espaços são fundamentalmente orientados pela localização das portas. Quando uma porta muda de lugar, o fluxo da circulação, principalmente aquele que atravessa os diversos aposentos, muda também. Além disso, quando existem portas, sua abertura une os cômodos, compondo um todo integrado, e sua localização determina as diferentes combinações possíveis entre eles.
A análise da sintaxe dos espaços permite chegar aos princípios combinatórios mais correntes como também avaliar o valor intrínseco que cada arranjo possui e deduzir as aspirações e a maneira própria de um indivíduo ou de um grupo organizarem o espaço.

A situação real, no entanto, é caracterizada por indivíduos vivendo em moradias não concebidas especialmente para eles nem por eles. Os profissionais constróem tomando por base as necessidades de um morador imaginário, típico de uma determinada classe social, que é sempre fictício. A escassez de recursos obriga, muitas vezes, a grande maioria das pessoas a aceitarem tais plantas. E, mesmo quando é possível construir uma casa personalizada, é provável que, um dia, ela se torne ultrapassada em relação às necessidades de seus proprietários.

Ora, os indivíduos e os grupos em um contínuo processo de transformação se modificam. Uma estrutura fixa dificilmente se adapta ao perpétuo movimento que caracteriza a vida. É claro que a porta enquanto estrutura com topologia variável se ajusta melhor às necessidades humanas e pode apresentar a solução deste impasse. Uma "porta em espera", isto é, a instalação, em todas as paredes comuns aos cômodos de uma casa, de uma estrutura espacial semi-fixa, que poderia ser facilmente transformada em divisória móvel, possibilitaria uma melhor adequação dos espaços às necessidades cambiantes dos seres humanos. Assim, o proprietário poderia, ele mesmo, modificar sua casa com o passar do tempo, segundo suas necessidades, sem grandes custos de tempo, energia e dinheiro.

Dispondo de uma tal estrutura, o habitante seria, sem dúvida, mais atento à adequação dos espaços às suas necessidades porque saberia, desde o início, que ele poderia corrigir as impropriedades de seu apartamento, por exemplo. Assim sendo, poderia personalizar seu espaço e experimentar um forte sentimento de identificação e pertencimento (Íñiguez \& Pol, 1996). As relações homem-ambiente se tornariam mais dinâmicas porque os habitantes participariam de forma ativa na criação de sua morada.

\section{A porta no espaço social}

O enquadramento das relações do indivíduo com a porta na ordem social é imprescindível a esta análise, tendo em vista não existir meio físico que não seja também um meio social (Ittelson et al.,1974). A partir do momento em que o social é levado em consideração, observa-se que a porta perde sua neutralidade porque o sujeito passa a atribuir-lhe valores e deixa de ser imparcial diante dela.

Ora, no espaço social a primeira realidade a ser considerada é a existência do outro: o outro, com seus pensamentos, suas ações e suas possessões - espaço e objetos. Nessa perspectiva, é possível ver a sociedade como um campo de portas colocadas, às vezes por mim mesma, às vezes pelos outros, e atribuir uma conotação social às suas funções físicas, uma vez que ela é interposta para materializar uma barreira psicológica ou social ou para criar um contato.

A porta do outro deve ser respeitada. Diante dela não existe liberdade de escolha entre a abertura e o fechamento. 
Não se tem o direito de intervir: resta render-se e aceitá-la tal como se apresenta. Por conseguinte, quando não se trata de seus próprios domínios, o sujeito prefere a porta em posição aberta. Nesta situação, a dialética do eu e da sociedade é substituída pela dialética das portas abertas e fechadas, e parece haver predominância de um de seus aspectos - abertura ou fechamento - na percepção dos indivíduos segundo sua posição e seu papel no espaço (Cavalcante, 2003).

Só muito raramente uma porta aberta se torna uma coerção porque permite sempre a escolha entre entrar ou permanecer do lado de fora; já uma porta fechada, que não se pode abrir, é um entrave à ação.

\section{O conceito de porta}

É importante ressaltar que a porta não é somente um elemento material, uma estrutura espacial, mas também um conceito, uma noção que se aplica a múltiplas situações da vida cotidiana.

Graças à abstração, existe um conceito interiorizado, percebido pelos sentidos, sobre a natureza inteligível da porta. Certamente, tal conceito é conhecido intuitivamente e freqüentemente está presente em muitas expressões lingüísticas - "Treino contínuo foi a porta de seu sucesso"; "A inflação está batendo novamente à porta”; "A universidade lhe fechou a porta”. A metáfora da porta facilita a compreensão de determinadas situações vividas e muitas vezes expressa o que não pode ser formulado nem compreendido de outra maneira. Mas quando a formulação do conceito é solicitada, existe uma vacuidade do espírito que autores como Bachelard, Flusser, Heidegger não preencheram.

Os dicionários atribuem à palavra "porta" diversos significados, sendo o mais evocado aquele que se refere à estrutura espacial móvel. Entretanto, em todas as definições, assim como em várias expressões em que a palavra "porta” é utilizada, seja qual for o campo de aplicação ao qual ela se refira, percebe-se que existe um núcleo comum de significação que permanece e que é imutável. Este núcleo constitui a essência mesma do conceito.

Dois exemplos de porta - uma material e outra metafórica - ampliam essa compreensão: "Maria abre a porta de sua casa para seus amigos e a fecha para seus inimigos"; "O concurso vestibular para a Universidade de Fortaleza realizou-se no mês de dezembro. Dez mil alunos participaram. Seis mil foram selecionados porque obtiveram média acima de 70 pontos em um escala de 100.”

Existem analogias entre as duas situações. No primeiro caso, a divisória móvel perfaz uma abertura ou um fechamento topológico segundo os critérios de Maria. Aqui a referencia é a porta material. Na segunda situação, houve também uma abertura (seis mil pessoas acederam à Universidade) e um fechamento (quatro mil ficaram reprovadas) segundo os critérios estabelecidos. O fluxo dos que passaram, assim como o fluxo daqueles que foram barrados, testemunham a existência de uma porta, apesar de sua imaterialidade. Tal porta cumpre função idêntica àquela realizada pela estrutura espacial. Nas duas situações um fluxo limitado de indivíduos passa de um domínio a outro segundo uma regra em vigor: “a decisão de Maria”, “a média mínima de 70 pontos".

A porta é então a lei que restringe um fluxo qualquer de um domínio a outro. Como ela é sancionada? Por que, quando e onde é sancionada? O que ela sanciona e por quem é sancionada? Todos estes pontos variam. O que permanece constante é seu caráter restritivo. Observe-se o quanto esta analogia é vizinha das intuições de Kurt Lewin (1946/1976) sobre o campo topológico dos valores. Alguns valores desejáveis do campo são separados de mim por uma zona seletiva (o concurso, a porta de entrada, etc.), outros estão presentes de imediato.

De fato, é o caráter restritivo desta lei que cumpre a função "porta” porque introduz um obstáculo ao fluxo, isto é, “o fechamento da abertura”, caracterizando assim a sua natureza dual. Deste ponto de vista, “o fechamento” é uma criação do homem, enquanto a abertura seria o estado natural. Esta oposição é similar àquela que existe entre espaço construído e espaço aberto. Na gênese da porta, está o fechamento criado pelo muro dando origem à abertura. No entanto, o homem não constrói um muro para depois abrir uma porta. Ele fecha o espaço dando forma à abertura. Em seguida, cria a divisória móvel para fechá-la. Contudo, se a porta nasceu para fechar a caverna, um dado imediato foi oferecido ao homem pela natureza: um dentro e um fora. Teria sido então a abertura da caverna que o homem fechou com uma pedra, um pedaço de madeira, um tapume, um tabique móvel qualquer.

Assim, cada porta material abriga em si sua forma imaterial, a saber, uma lei própria que comanda sua abertura e seu fechamento. Isto significa que, para ultrapassá-la, não basta estar frente a ela e ter a capacidade física de abri-la. É preciso se conformar à lei em vigor, isto é, poder transpor a porta imaterial nela embutida, como, por exemplo, receber a permissão do habitante do local, poder pagar o bilhete de entrada, demonstrar o conhecimento necessário para freqüentar o curso, etc.

As leis que regem o movimento das portas podem ser chamadas de "leis de acessibilidade" ou "leis de acesso", pois, em realidade, elas constituem a essência do conceito porta, a estrutura material sendo apenas sua representante.

\section{A porta: um princípio de organização}

É concebível comparar a porta a uma válvula que controla a saída de um fluxo, porque, a exemplo da teoria dos sistemas, ela é um centro de decisão que recebe informações e as transforma em ações objetivando aumentar ou diminuir a intensidade dos fluxos que lhe acorrem, deixando-os passar ou não.

Se essa imagem é verdadeira, a porta pode ser considerada um "pólo de atração" tal qual definido na Teoria de Campo (Lewin, 1944/1976), e isso acontece porque uma porta esconde sempre alguma coisa atrás de si. Não obrigatoriamente um bem, mas um outro espaço, um lugar que, por ele mesmo, pelos objetos que abriga, pela posição topológica ou social que proporciona, é susceptível de interessar a uma ou mais pessoas, em um momento qualquer. Em japonês a palavra 
porta, guen-kan, significa controle do invisível, do desconhecido.

Para alargar essa compreensão, atente para o exemplo da porta de um teatro onde se representa uma boa peça. Os que querem assisti-la são mais numerosos do que os lugares disponíveis. A função da porta é então a de controlar a entrada para impedir a superlotação do local, preservando assim o bem-estar daqueles que aí se encontrarão. Nessa configuração percebe-se que pouco importa o gênero da porta ou a razão de sua existência. Seu objetivo último será sempre o mesmo: distribuir no ambiente os indivíduos e objetos de maneira a evitar conflitos, conseguindo desse modo que a sociedade permaneça um todo diversificado e equilibrado.

A porta é, por conseguinte, uma estrutura espacial que serve à organização funcional da sociedade tal como concebida por Moles e Rohmer (1978):

O objetivo da organização funcional do sistema social é o de permitir a grupos diferentes perseguir objetivos diferentes com valores e ideais diferentes sem procurar necessariamente colocá-los em harmonia, mas atentando para que eles não se destruam uns aos outros e não destruam a armadura do sistema (p.171).

\section{As portas: elementos de um equilíbrio}

O ritmo de abertura e fechamento das portas dos serviços públicos e privados e do comércio de uma cidade segue um "horário-tipo" que visa à conveniência da maioria dos habitantes e traduz ao mesmo tempo a cultura local. Na verdade, o ritmo de vida dos habitantes influencia o horário de abertura e fechamento das portas e esse, por sua vez, influencia o ritmo de vida. Esse horário pode, entretanto, impor constrangimentos, principalmente quando não atender mais a maioria do público usuário destes locais. É o caso de algumas regiões onde, ao mesmo tempo em que estes serviços estão abertos, a grande maioria da população trabalha e se encontra na impossibilidade de ir às compras. Uma modificação no ritmo de abertura e fechamento das portas dos estabelecimentos comerciais tem sido necessária para a manutenção ou retomada do equilíbrio. Esta é a proposta do comércio dos shopping centers que permanece aberto até as 22 horas, de segunda a sábado, e cumpre um horário especial aos domingos.

Nessa perspectiva, a opção que a porta oferece entre aberta e fechada ganha destaque porque, como um disco de retroação negativa, sua "ação", diante de uma mudança, pode ser alterada, de maneira a corrigir uma disfunção e garantir a estabilidade do sistema; do contrário, um desequilíbrio apareceria, a harmonia vigente seria rompida, e tais portas poderiam se constituir em objeto de mal-estar social. Assim sendo, é lícito dizer que as portas também contribuem para a manutenção do equilíbrio social.

\section{A porta: manutenção da hierarquia social}

O indivíduo está continuamente atravessando portas, sejam elas materiais como a porta de entrada de sua casa ou de um cinema, sejam elas imateriais como o concurso para um emprego ou exame médico para freqüentar uma piscina - portas mais ou menos numerosas e/ou resistentes, conforme a natureza dos alvos que protegem e o valor que lhes é atribuído pelo conjunto de indivíduos de uma sociedade. A raridade e os benefícios proporcionados são alguns dos coeficientes que definem o valor social de um objetivo.

Note-se que quanto mais um objetivo é valorizado, tanto mais sua acessibilidade é reduzida. Comparem-se, por exemplo, o controle que existe à entrada de um teatro onde os alunos de um colégio apresentam uma peça e aquele exercido à entrada de um teatro onde os melhores atores nacionais encenam. Para o primeiro tipo de representação, geralmente a entrada é gratuita; para o segundo, freqüentemente se faz necessário reservar com antecedência para se conseguir um ingresso, comumente vendido a preços acessíveis apenas a poucos. Relacionem-se ainda os passos e conhecimentos necessários a um vendedor de cachorro quente, com aqueles indispensáveis a um professor universitário.

Estes exemplos mostram que alvos mais valorizados são sempre mais difíceis de se alcançar, em oposição a objetivos ou lugares menos visados, cuja aproximação é mais fácil de ser empreendida e pode ser alcançada por muitos. Por conseguinte, a acessibilidade está ligada também a capacidade dos indivíduos, de atravessar portas e, conseqüentemente, chegar a seus objetivos.

Assim, quando o número de portas que precede determinados objetos aumenta, o número de indivíduos a transpôlas diminui. Observa-se, portanto, que a seleção realizada pelas portas dispõe os indivíduos em forma de pirâmide, cuja base é formada por aqueles que logram objetivos de menor valor ou mais acessíveis. Progredindo em direção ao topo, encontramos os indivíduos com maior habilidade para atravessar portas.

A habilidade de um indivíduo em atravessar portas repousa em suas capacidades inatas ou adquiridas e, sobretudo, em seu poder social, compreendido aqui como o capital (Bourdieu, 1996) sócio econômico e cultural de um indivíduo que lhe permite dominar o universo social considerado e/ou estabelecer relações que concorram para a manutenção ou alteração desse poder. De fato, a habilidade de um indivíduo em atravessar portas está em relação íntima com seu poder social. Esta reflexão permite relacionar a pirâmide de indivíduos delineada pela porta àquela traçada pela hierarquia social existente em determinada sociedade. A partir dessa reflexão, é aceitável considerar-se a porta como uma instituição social cujo objetivo é manter a hierarquia vigente, agindo como um mecanismo de proteção do poder.

Entretanto, uma observação mais cuidadosa constata que a hierarquia social nem sempre corresponde a uma hierarquia de valores. Sem dúvida, teoricamente, a função da porta é a de controlar para que os objetivos sejam alcançados por sujeitos merecedores. No entanto, na prática, muitos chegam ao topo burlando portas, sem direito de aí estar. Certamente qualquer um conhece e pode rememorar exemplos de pessoas que ocupam cargos sem as prerrogativas necessárias para tal. O poder social que lhes permitiu galgar tal posição é, nesses 
casos, vazio das qualificações exigidas, seus propósitos tendo sido alcançados por meio de uma "liberdade marginal“" que Moles e Rohmer (1998) definem como "a extensão do campo de liberdade do indivíduo resultante da elasticidade das fronteiras da lei que permitem ser ultrapassadas em uma direção qualquer, na medida em que o indivíduo exerce um esforço" (p. 50).

\section{A porta como elo entre poder espacial e poder social}

Poder espacial significa liberdade de deslocamento, quer dizer, acesso a diferentes tipos de espaço e, também, na maioria das vezes, poder de controle sobre o fluxo de visitantes. Por um lado, o poder espacial está diretamente condicionado às características topológicas dos espaços, assim como ao valor que é atribuído a sua posição ou ao bem que ele guarda. Quanto mais valorizados forem, tanto maior será o poder daquele que a eles tem acesso. Por outro lado, o poder espacial está também atrelado às qualificações do próprio indivíduo as quais lhe permitem ou não acesso aos espaços, independentemente do grau de acessibilidade atribuído ao lugar em si.

O estudo da habilidade ou capacidade em atravessar portas, tal qual esboçado acima, tem mostrado que o poder espacial está intimamente vinculado ao poder social do indivíduo. Esta relação existe porque, geralmente, aqueles que detêm o poder social têm em mãos também os meios de procurar um poder espacial mais vasto. Mas o inverso também é verdadeiro. E, talvez, seja por esta razão que aqueles que detêm o poder social tentam monopolizar o espaço.

O caso das empregadas domésticas, a quem os detentores de poder legal permitem um domínio espacial exorbitante, é uma exceção notável a esta regra geral, e, certamente, eles não o fazem sem tentar limitar e controlar este poder por outros meios. Isto coloca problemas interessantes aos sociólogos. Por exemplo, quais são os controles de segurança das empregadas em um laboratório secreto de armamento? Assim, no interior da casa a que ela tem acesso, existem sempre lugares, móveis ou ambos que lhe são interditados; a retirada de objetos de grande valor para locais mais seguros visam à proteção contra ladrões, mas também contra a empregada. Entretanto, o mais importante mecanismo de controle de poder da empregada é a segregação. Para facilitar suas tarefas, mas também para excluí-la do grupo, esta funcionária geralmente trabalha durante as horas em que os locais estão mais vazios. E, tratando-se de uma empregada a tempo integral, élhe atribuído um local particular e mesmo, quando possível, uma porta de entrada específica com a intenção de lhe sinalizar o lugar que lhe é devido.

\section{Seriam as portas mais fechadas do que abertas?}

O vai e vem entre interior e exterior se faz através da porta. Observando sua posição e seu ritmo de abertura e fechamento, se conhece a relação que o habitante tem com o exterior, isto é, com os outros e com a sociedade de uma maneira geral.

Atualmente as portas de entrada dos espaços privados estão mais fechadas do que abertas. A porta que vela, a porta que acolhe, própria das comunidades pré-industrializadas, não existem mais. Hoje cada um está bem trancado atrás de sua porta, senão blindada, pelo menos munida de algumas três fechaduras.

O fenômeno da porta fechada traduz o medo latente que reina em nossas cidades. O individualismo e a solidão impostos pela sociedade industrializada são, em última análise, responsáveis por esta apreensão. Segundo Moles e Rohmer (1978), nosso sistema social, contrariamente àquele da época clássica, não constitui mais uma instituição unitária, mas um conjunto de agregados com portas fortes que não compartilham objetivos, mas uma rede de serviços e incômodos que devem usar e, se possível, abusar. Tais reflexões conduzem à conclusão natural de que só uma mudança na sociedade poderá novamente modificar este estado da porta.

Ora, as análises que realizei (Cavalcante, 1982) mostraram que o ritmo de vida influencia a dinâmica de abertura e fechamento da porta e esta, por sua vez, influencia o ritmo de vida. A expressão "ritmo de vida", aqui, não se restringe ao fenômeno temporal; significa também "modo de vida”, maneira de viver, de agir e de pensar. Sendo procedentes essas afirmações, é admissível pensar-se que uma mudança na posição predominante da porta ocasionará uma mudança social. Será isto possível?

Certamente a sociedade não nos satisfaz. Somos todos descontentes com o modo de vida que ela nos impõe. Mas o que fazer? Mudar a sociedade se configura como tarefa muito complexa e de difícil execução. Contrariamente, modificar a porta parece ser uma tarefa mais definida e mais fácil de ser empreendida. E, se ainda por tal meio se chegar a uma mudança social, por que não a empreenderíamos?

Em que consistiria então “mudar a porta”? Em termos mais gerais, significaria colocá-la na posição aberta. Contudo este não seria apenas um ato cinestésico, mas todo um processo que deveria se iniciar pela alteração de seu sistema de segurança atualmente fundado na segurança eletrônica. Tal sistema, quando implantado em sua totalidade, realiza uma vigilância sem dúvida eficaz, porém a um preço muito alto: a perda do sentimento de convivialidade que uma porta de entrada deve também transmitir.

Por conseguinte, a solução se encontraria no restabelecimento da vigilância natural, igualmente eficaz e muito menos agressiva. Tal sistema, como pensou Newman (1972), se assenta, num primeiro momento, sobre os elementos do design arquitetural: 1) imóveis menores que permitam uma apropriação mais fácil das áreas comuns; 2) imóveis situados próximos das vias publicas e possuindo uma maior permeabilidade entre o interior e o exterior para permitir: a) uma vigilância das áreas comuns e dos espaços públicos conexos, pelos habitantes, a partir de seus apartamentos; b) o exercício do controle social provindo dos espaços públicos sobre os espaços semiprivados internos. A isso se acrescentaria a presença de um porteiro. A perda de intimidade - primeira acusação que se faz à instituição desse serviçal - não seria maior que aquela ocasionada por um sistema de vigilância com câmeras de circuito fechado. 
A longo prazo, economizar-se-ia em relação ao que se paga em crime, insegurança, desemprego de pessoas e em relação ao preço dos gadgets e sistemas de segurança individuais. (Sommer,1974). Por outro lado, a vigilância natural reduziria o medo e a ansiedade dos habitantes, que, sentindose em segurança, freqüentariam mais os espaços comuns trazendo, por sua vez, maior cuidado e proteção aos ambientes.

Dessa forma, seria estabelecido um novo ciclo que asseguraria ao mesmo tempo vigilância e acolhimento. A sociedade mudaria também porque, pouco a pouco, o espírito de comunidade originado restabeleceria a confiança no outro, a começar pelos vizinhos.

A tese de que uma alteração no uso de um elemento espacial levará a uma mudança social pode parecer insuficiente e pouco concebível. Mas há quem acredite nela e proponha a integração com a rua, a realidade e o cotidiano da cidade através de prédios sem grade, calçadas parcialmente gramadas com banco de madeira e vigilância exercida por alguém conhecido da vizinhança. Estas são as características do prédio de número 65 da rua General Jardim, no centro de São Paulo, onde funciona a Escola da Cidade, primeira faculdade de arquitetura criada e gerida pelos arquitetos que nela lecionam. Os profissionais da instituição acreditam que viver enclausurados por conta do medo gera mais exclusão e, conseqüentemente, mais violência. Ciro Pirondi, diretor de Escola, julga que "a melhor crítica que podemos fazer a uma poesia é compor outra em seu lugar” (Gazeta Mercantil, 24 agosto 2002, p. 2).

\section{Atravessar a porta}

$\mathrm{O}$ ato de passar por uma porta se compõe de três tempos - antes, durante e depois da porta - caracterizados todos, pelo mesmo objetivo funcional, a passagem, que os identifica respectivamente como preparação, passagem propriamente dita, e adaptação ao novo espaço ou domínio de ação. Tratese de uma porta material ou imaterial, estas três fases estarão sempre presentes em qualquer ato de passagem.

Os componentes funcionais deste ato se juntam a outros de cunho simbólico, identificados como rituais. Às vezes, o ato ou micro-ato funcional é, ele mesmo, revestido de tal caráter. Por exemplo, a convenção de "bater à porta" ao mesmo tempo em que anuncia uma presença, é também expressão de respeito em relação ao território do outro.

As ações funcionais - andar em direção à porta, manipular a chave... - têm por objetivo permitir ao indivíduo chegar ao outro lado. Os rituais, por sua vez, visam a afastar os efeitos negativos que o ingresso no novo espaço possa ocasionar.

A passagem por uma porta consiste sempre em uma mudança, seja de ambiente, seja de nível, de domínio ou de vida. Os rituais são símbolos de iniciação. É importante lembrar que os romanos e muitas outras civilizações criaram os deuses da porta - Limes. Segundo esta regra da teogênese (Moles \& Rohmer, 1998), todo fenômeno imprevisível, não controlável ou não enunciável por leis científicas, como a entrada de um visitante, tem, de alguma forma, algo a ver com um sagrado localizado. Por isso a ausência de ritual se constitui em violação e, assim como a inexatidão de um ato funcional, pode chegar a impedir o acesso. A desaprovação social que se manifesta nestas ocasiões age em feedback assegurando a continuidade destas práticas que são inscritas no repertório cultural de uma sociedade desde tempos menos civilizados.

$\mathrm{O}$ automatismo hoje comum à abertura de portas representa, em geral, uma busca pouco louvável, do menor esforço, porque introduz modificações estruturais ao ato da passagem. Certamente nesses casos há economia e facilidade de movimentos. No entanto, o papel da porta como ponto de encontro social tende a desaparecer. Como seria o modo de vida em uma sociedade de portas automáticas, em que os atos necessários às passagens obrigatórias fossem totalmente suprimidos ou modificados, mas na qual o controle social se mantivesse de forma integral ou fosse reforçado pelas magias da eletrônica aplicada - formulas secretas, palavras chave, identificação vocal -, conduzindo ao contato com um social impessoal, diferente da imagem de um outro presente e identificável? Reduzir a mobilidade indefinida dos indivíduos, construindo muros e portas, parece ser um procedimento constante da sociedade em nossos dias. Seria este o ideal de uma cristalização social? Enfim, percebe-se, através destas reflexões, todo um domínio possível de exploração sobre a vida cotidiana.

\section{Conclusão}

A porta constitui a síntese harmoniosa de duas estruturas topológicas opostas: a abertura e o fechamento. Ao longo deste trabalho foram explicitadas e identificadas numerosas funções cumpridas por esta reunião topológica, o que permite qualificá-la como uma estrutura espacial rica.

Suas funções se agrupam em duas séries distintas, cada uma favorecendo, grosso modo, um valor específico. As funções preenchidas pela porta fechada dão prioridade ao valor proteção; aquelas desempenhadas pela porta aberta privilegiam a comunicação.

Por sua própria natureza e para que possa cumprir seu destino, a porta deve estar aberta ou fechada. Certamente, estes dois estados acontecem em tempos e durações diferentes, mas um não deve jamais anular o outro. Quando há exclusão de um deles, o papel da porta em relação ao contexto ambiental deve ser revisto: ou o ambiente mudou, e a necessidade de uma porta não existe mais, somente a abertura ou o fechamento sendo necessários; ou ocorreu uma mudança na função da porta, que deverá ser reavaliada sob pena de provocar um desequilíbrio no meio ambiente. A velha porta abandonada coberta pela hera que se reduz lenta e docemente ao estado de muro assim como a porta do templo, sempre aberta ou sempre fechada por usos acidentais ritualizados, levam à reflexão destes casos limites.

Estrutura compacta, ocupando um mínimo de espaço, a porta satisfaz comodamente três grandes necessidades da vida humana no espaço social: proteção, comunicação e passagem. Existe um outro meio que faça tanto com tão pouco?

Apesar de as abordagens que compõem este trabalho versarem principalmente sobre a porta enquanto estrutura 
espacial, foi possível observar que o conceito porta e muitas das conclusões aqui arroladas se aplicam ao sistema social em seu conjunto.

De fato, toda a vida social se exprime através de portas. Os indivíduos e os grupos, tão bem quanto os objetos, estão distribuídos no espaço estruturado por portas que regulam as relações de maneira a manter a ordem social dentro de um certo equilíbrio. O tipo de porta, o local onde ela se encontra, a razão pela qual ela existe variam segundo as situações e a sociedade em análise, e a resposta a estas questões permitirá aprofundar seu estudo. Conhecendo as portas, conhecemos a sociedade.

Ao longo desta reflexão foi-nos dado perceber como o estudo de um elemento espacial nos possibilita conhecer muitos aspectos de nossa vida em sociedade. Vimos também como a idéia de porta, plena de valores e mitos, é significativa para o ser humano socializado. Finalmente, tornou-se-nos evidente que na sociedade nada é deixado ao acaso: a lógica humana está por toda parte.

\section{Referências}

Bourdieu, P. (1996). Razões práticas. São Paulo: Papirus.

Cavalcante, S. (1982). Psychosociologie de la porte: outil d'une topologie variable. Tese de doutorado não-publicada, Université Louis Pasteur, Strasbourg, França.

Cavalcante, S. (no prelo). A porta: objeto dos espaços humanos. In R. S. L. Guzzo, J. Q. Pinheiro \& H. Gunther (Orgs.), Psicologia Ambiental: entendendo as relações do homem com o seu ambiente. Campinas: Alínea.

Gregory, R. L. (1988). Odd perception. Nova York: Routledge.

Íñiguez, L., \& Pol, E. (1996). Cognición, representación y apropiación del espacio. Barcelona: Publicacions de la Universitat de Barcelona.
Ittelson, W. H., Proshansky, H. M., Rivlin, L. G., \& Winkel, G. H. (1974). An introduction to Environmental Psychology. Nova York: Holt, Rinehart \& Winston.

Latour, B. (1992). Where are the missing masses? Sociology of a door. In W. Bijker \& J. Law (Orgs.), Shaping technology - building society. Studies in sociotechnical change (pp. 225-259). Cambridge: MIT Press.

Lewin, K. (1976). Behavior and development as a function of the total situation. In D. Cartwright (Org.), Kurt Lewin: Field Theory in Social Science (pp. 238-303). Chicago: The University of Chicago Press. (Original publicado em 1946)

Lewin, K. (1976). Constructs in Field Theory. In D. Cartwright (Org.), Kurt Lewin: Field Theory in Social Science (pp. 30-42). Chicago: The University of Chicago Press. (Original publicado em 1944)

Moles, A. (1972). Théorie de l'Information et perception esthétique. Paris : Denoël/Gonthier

Moles, A., \& Rohmer, E. (1978). Psychologie de l'espace. Tournai, Bélgica: Casterman.

Moles, A., \& Rohmer, E. (1998). Psychosociologie de l'espace. Paris: L'Harmattan.

Newman, O. (1972). Defensible space. Nova York: Macmillan.

Pagenotto, M. L. (2002, 23, 24 e 25 de agosto). O resgate do verdadeiro significado de cidade. Gazeta Mercantil, p. 2.

Proshansky, H. M., Ittelson, W. H., \& Rivlin, L. G. (1976). Freedom of choice and behavior in a physical setting. In H. M. Proshansky, W. H. Ittelson \& L. G. Rivlin (Orgs.), Environmental Psychology: people and their physical settings (pp. 170-181). Nova York: Holt, Rinehart \& Winston.

Schwach, V. (1989). La micropsychologie des rapports homme-machine dans la vie quotidienne. In M. Mathien, V. Schwach, G. N. Fischer, V. Alexandre \& J. M. Mouchot (Orgs.), La physique des sciences de l'homme. Strasbourg: Oberlin.

Sommer, R. (1974). Tight spaces: hard architecture and how to humanize it. Englewood Cliffs, New Jersey: Prentice-Hall.

Sylvia Cavalcante, doutora em Psicologia Ambiental, Université Louis Pasteur, Strasbourg, França, é Professora Titular no Programa de Pós-graduação em Psicologia da Universidade de Fortaleza (CE). Endereço para correspondência: Rua Vilebaldo Aguiar, 95 apto. 1002; Fortaleza, CE; 60190-780. Telefax: (85) 262-0891. Email:sylviac@secrel.com.br, ou sylviac@unifor.br 